\title{
Chronic Lymphocytic Leukemia and solid and hematological second neoplasms: a real association?
}

\author{
Leucemia Linfóide Crônica e segundos neoplasmas sólidos e hematológicos: uma \\ associação real?
}

Arthur Youssif Mota Arabi ${ }^{1}$, Vitória Espíndola Leite Borges ${ }^{1}$, Fernando Sérgio Blumm Ferreira ${ }^{1,2}$, Flávia Dias Xavier ${ }^{1,2}$

\begin{abstract}
The Chronic Lymphocytic Leukemia is the most common cause of Leukemia in adults, corresponding to $30 \%$ of the total amount of the cases of leukemia diagnosed nowadays. One of the greatest challenges regarding its clinical management is related to the greater risk of developing secondary diseases, in especial the appearance of hematological and solid neoplasms. It is thought that the immunosuppression induced by the leukemia and by the chemotherapeutic treatments, the genetic features intrinsic to each individual, and some risk factors (such as smoking and solar exposure) have a key role in facilitating the appearance of those secondary malignancies. The patients with leukemia need to go through a more careful follow-up, intending to monitor the emergence and treatment of those possible secondary malignancies, in order to achieve a better prognosis and a better quality of life.

Keywords: Leukemia, Lymphocytic, Chronic, B-Cell. Hematologic Neoplasms. Neoplasms, Secondary Primary

\section{RESUMO}

A Leucemia Linfóide Crônica (LLC) constitui a forma leucêmica mais comum em adultos, correspondendo a $30 \%$ do total de casos de leucemia diagnosticados atualmente. Um dos grandes desafios relacionados a seu manejo clínico diz respeito ao maior risco de desenvolvimento de doenças secundárias, dentre as quais se destacam os neoplasmas sólidos e hematológicos. Estima-se que a imunossupressão induzida pela própria leucemia e pelos tratamentos quimioterápicos, as características genéticas intrínsecas a cada indivíduo e alguns fatores de risco (como tabagismo e exposição solar) tenham papel atuante na facilitação do aparecimento desses segundos neoplasms. Os pacientes portadores de LLC precisam passar por um acompanhamento clínico mais próximo e cauteloso, na intenção de monitorar o aparecimento e tratamento de eventuais segundas malignidades, a fim de se obter um melhor prognóstico e uma qualidade de vida mais adequada.
\end{abstract}

Descritores: Leucemia, Linfocítica, Cronica, Célula B. Neoplasias Hematológicas. Neoplasias, Primária Secundária

1. University Hospital of Brasilia, Internal Medicine - Brasilia - Federal District - Brazil

2. Hospital Sírio Libanês, Center of Oncology - Brasília - Federal District - Brazil

Financial support: none to declare.

Conflicts of interest: None of the authors has any kind of conflict of interests regarding this work or its theme.

Correspondence author: Arthur Youssif Mota Arabi. University Hospital of Brasilia, Internal Medicine - Brasilia - Federal District - Brazil 604/605 - Asa Norte, Brasília - DF, 70840-901.

E-mail: arthuryoussif95@gmail.com 
The Chronic Lymphocytic Leukemia (CLL) is a B cell neoplasia, marked by the accumulation of matures lymphocytes (CD5+, CD19+, CD23+), whose natural course may vary from a asymptomatic condition to rapidly progressive cases. ${ }^{1} \mathrm{CLL}$ is the most prevalent leukemia in westerns adults, with an annual incidence estimated in 4,2 new cases in 100.000, corresponding to $30 \%$ of all leukemia. It shows a peak of incidence in elderly patients, and the average age of diagnosis is at 67 years old. ${ }^{2,3}$

Despite of the improvement in treatment and the longer prognosis, the biggest challenge in managing these CLL patients continues to be the complications in the longterm follow-up. Those include the complications related to the CLL - such as infections and the development of autoimmune diseases - and those related to the elevated incidence of secondary neoplasms. ${ }^{4}$

Patients with CLL have a greater risk of developing other neoplasms, when compared with the general population. ${ }^{5}$ The risk factors in those cases may be: prolonged immunosuppression related to the disease and its chemotherapies drugs; genetic predisposition of each patient; carcinogenic potential of the chosen chemotherapy (or radiotherapy); risk factor associated to life habits (such as solar exposure and smoking); and also the increase in medical surveillance in patients CLL carriers, when comparing to healthy individuals. ${ }^{4,5,6,7,8}$

Actually, those patients are more susceptible to the appearance of malignancies, whether they are hematologic or solid neoplasms, what makes the periodic monitoring of the LLC patient extremely important.

\section{Secondary Neoplasia}

There are plenty of studies that indicate that the risk of developing a second cancer is significantly higher in patients with $\mathrm{CLL}^{7,9,10}$, being two to five times more likely, when comparing with the population of same age (and this rate is constant during time) ${ }^{4,11,12}$. Besides that, among patients with CLL e secondary neoplasms, those new cancers had an intimate relation with the death cause in almost half of cases.

Non-hematologic neoplasms also occur with a greater frequency in carriers of CLL. ${ }^{13}$ A study conducted by TSIMBERIDOU et al. showed that, among 2028 patients accompanied between 1985 and 2005 at the University of Texas MD Anderson Center, 551 patients showed other neoplasms, beyond the CLL, which were diagnosed at the time of the diagnosis of CLL or during the follow-up. ${ }^{5}$ Among the types of cancer most typically associated with CLL, by the quoted paper, we may highlight (in a decreasing order of frequency: skin, prostate, breast, melanomas, gastrointestinal tumors, lung neoplasms. Some papers state that the higher risk of development of neoplasms in carriers of CLL overcomes in $2-3$ times the risk in the control population (when comparing groups of same genre and age). ${ }^{5,13,14}$
In a study recently published by Falchi et $\mathrm{al}^{12}$, in which there were accompanied 797 patients with CLL (with a follow-up higher than 10 years since the diagnosis), $23 \%$ were diagnosed as having a secondary neoplasia after CLL (that had not been treated yet) and $41 \%$ were diagnosed with a secondary malignancy after finishing the treatment of CLL. The second most common neoplasia found was the non-melanoma skin cancer, followed by the prostate cancer, breast cancer, melanoma, lung cancer and leukemia, independently if the patient has or has not received treatment, once that, at this cohort, the administration of therapy had not shown any influence in the emergence of new cases of neoplasia. Similar data was found in a cohort of 13,589 patients diagnosed with CLL, with the incidence of 13,1\% of other neoplasms, highlighting the following cancers: lung, melanoma, prostate, colorectal and renal. Those patients also presented greater risk of developing the smoking-related cancers, such as lip, mouth, pharynx, larynx, lung, kidney and bladder cancers. ${ }^{11}$

In another analysis, Hisada et al $^{9}$ conducted a study of 16,367 patients diagnosed with CLL, using the database of SEER (Surveillance Epidemiology and Results Program). The study observed elevated risk of developing (Observed / Expected): Kaposi Sarcoma ( $\mathrm{O} / \mathrm{E}=5,09)$, malignant melanoma $(\mathrm{O} / \mathrm{E}=$ $3,18)$, larynx cancer $(O / E=1,72)$ and lung cancer $(O /$ $E=1,66)$. When analyzing men, it was found a higher risk of cerebral cancer $(O / E=1,91)$. In women, it was observed a higher risk of stomach cancer $(\mathrm{O} / \mathrm{E}=$ $1,76)$ and bladder $(\mathrm{O} / \mathrm{E}=1,52)$.

Morton et $\mathrm{al}^{7}$ also used the registers of the database of the SEER (from 1996 - 2006), evaluating 15915 patients with CLL, identified an elevated incidence of lung cancer, especially in younger patients (55 years average), after performing chemotherapy. Besides that, it was demonstrated higher rates of melanoma (in patients diagnosed before 70 years old), and a greater risk of developing colorectal and thyroid neoplasms. However, there was not found any difference of occurrence of neoplasms regarding to different genres. ${ }^{7}$

Another analysis of the SEER database, using 2 million of patients with multiple types of cancers (beast, lung, prostate, kidneys, ovaries, pancreas and colorectal) showed an overall reduction of survival in patients with cancer and pre-existing CLL, when compared to patients without CLL. This relation was even more preeminent in patients that carried breast, kidney, lung and colorectal cancers. The data, presented by Solomon et al., regarding the elevated risk of solid tumors after the diagnosis of CLL suggests that is important to submit those patients to an effective triage to discover those neoplasms, in order to perform an early detection of those malignancies, fact that may help in deciding with type of therapy will be chosen for each patient ${ }^{15}$

It is worth saying that those neoplasms that have developed after the diagnosis of CLL tend to behave in a more aggressive way, and they represent an important cause of death at this population. $8,15,12$ 
Kyass et al. ${ }^{9}$ affirmed that the development of cancers after CLL was responsible for 34\% of deaths in a cohort of patients. In another North American cohort, mortality by other neoplasms in patient with CLL was $64,8 \%$, not considering the lymphoproliferatives causes. ${ }^{11}$

\section{Risk factors associated to the development of the second neoplasia}

Male sex, advanced age ( $>60$ years old) and low platelets levels were found to be independent risk factors to develop a second malignancy. ${ }^{12,16}$ Others studies suggest association between the blood levels of Lactate Dehydrogenase (LDH), creatinine and beta-2 microglobulin with greater chances of developing a new neoplasia. ${ }^{6}$ Besides that, patients who carry a deletion at the sort arm of chromosome 17 (17p) present a slightly elevated incidence, when compared to LLC patients that do not have that chromosomal abnormality. ${ }^{5}$

The classification Binet Stage A and the presence of systemic comorbidities are also related to higher chances of developing second neoplasms. ${ }^{5}$ This fact is justified because these patients present a greater survival, when comparing to those classified as Binet Stages B or C (and, thus, this group of patients has more time to develop and discover another type of cancer). Similar results were found by Falchi at al. ${ }^{12}$, who said that the overall survival of patients that showed a second neoplasia was 22,9 years, while the survival of the patients that did not present with another neoplasia stayed in 16,2 years. These findings show some relation with the estimated average to develop a second neoplasia after the diagnosis of CLL (about 20 - 21 year), in patients who are correctly accompanied at the follow-up. ${ }^{4}$

There were not found significant data at the literature, so far, that associates the incidence of a second neoplasia and others LLC features, such as mutations at some genes (ZAP-70, CD38, IgVH) and cytogenetics.

\section{Therapies and Second Neoplasms}

The most recent studies are showing higher rates of second neoplasms after the diagnosis of CLL. Some authors say that these odds are two times bigger in patients who carry that type of leukemia, fact that seems to be related to the greater immunosuppressive effect of the current CLL therapies. ${ }^{17}$

The antimetabolites or the purine analogs (such as fludarabine) are commonly used as a weapon in the treatment of CLL patients. They are known to have an association with a mild myelosuppression and to promote profound immune alterations and prolonged immunosuppression, facts that put those patients in even greater risks. ${ }^{8}$
Studies developed by Cheson et al. ${ }^{10}$, with 724 CLL patients after isolated therapy with fludarabine showed an increase, at this group, at the frequency of new tumors, when compared to the general population (SEER data). These bigger rates were similar to those that were found in patients that carry CLL and were submitted to alternatives therapeutic plans, suggesting that the therapy does not add significant risks to the development of new cancers. However, it was noticed an increase at the risk of developing an second lymphoproliferative disease, after isolated treatment with fludarabine, ${ }^{24}$ especially in cases of Richter's transformation (incidence of $18 \%$ in patients treated with fludarabine against $6 \%$ at those who had never received treatment with this drug). ${ }^{19,20,21}$

In a similar way, Maddocks and Christianson et al. ${ }^{22}$ identified a higher tendency to develop a second lymphoproliferative neoplasia in patients previously treated with purine analogs (5,2\% of them), in relation to those who had received different therapies ( $2 \%$ of them).

A multicenter analysis evaluated the data of 521 patients (all of them carriers of CLL), in order to compare the rates of occurrence of others hematologic neoplasms in three different groups, all of them created using randomization. The first group received treatment with chlorambucil (191 patients); the second group received fludarabine (188 patients); the third one received chlorambucil and fludarabine (142 patients). ${ }^{23}$ In the group that was treated with the combination of both medications, it was observed 5 cases $(3,5 \%)$ that progressed to Myelodysplastic Syndrome (MDS) or Acute Myeloid Leukemia (AML) related to the chosen therapy. In the group that received only fludarabine, only 1 case $(0,5 \%)$ of MDS or AML was seen, and the group that received only chlorambucil did not show any new therapy-related hematologic condition. ${ }^{23}$ Vinsnetin et al. ${ }^{4}$, evaluating 795 patients with CLL, suggested that the use of purine analogs and alkylating agents can be connected to greater chances of developing skin cancer. ${ }^{4}$

The French Cooperative Group on Chronic Lymphocytic Leukemia conducted two big studies in Binet Stage A patients. In the first study, 609 patients were randomly assigned to be part of a group treated with chlorambucil and to another group that did not receive that drug. Beside the fact that it was not demonstrated difference related to overall survival, there was a significantly greater amount of second neoplasms in patients that used chlorambucil, especially when analyzing acute leukemias and breast, skin and colon cancers occurrence. In the second study, with 926 patients, a group received chlorambucil and prednisone during 3 years. Yet, it was not seen any difference in survival, and there was not observed any increase in the rate of occurrence of new tumors. ${ }^{24}$ 
In a cohort that accompanied 234 patients with CLL that received the FCR therapy (Fludarabine + Ciclofosfamide + Rituximab) it was noticed that they showed 2,38 times more chances of developing cancer, when compared to the general population, especially in women, persons older than 60 years, and those with Dehydrogenase Lactate twice bigger than the superior limit of normality. At this cohort, $28 \%$ of patients developed a second cancer - particularly skin cancer, AML and MDS - and 9\% evolved with Richter Syndrome after FCR treatment. However, this bigger risk is consistent with the expected rates of occurrence of new cancers in carriers of CLL. ${ }^{17}$

The average range between the beginning of FCR therapy and the appearance of a second malignancy was 3.1 years. ${ }^{17}$ A relatively high rate of AML and MDS was observed in patients treated with FCR in three different therapeutic schemes: the first, that received the standard scheme (FC), the second, that used 3 times greater doses of rituximab per cycle (FCR), and the third one, that used a combined therapy based at the fludarabine (FCR with mitoxantrone). The development of a second cancer after FCR affects negatively the overall survival, being significantly shorter in those patients, when compared with the general population. ${ }^{17}$ The phase 3 study CLL8, conducted by the German Chronic Lymphocytic Leukemia Study Group (GCLLSG), compared the incidence of second neoplasia in two different group of patients (one submitted to FC therapy and the other treated with FCR). It was seen a two times bigger chances of Richter transformation in the FC arm (6,3\%), when compared to the FCR arm (3,2\%), and the transformation, generally, started 2 years after the beginning of the treatment. The development of hematologic neoplasms and solid tumors (both secondary to CLL) presented with a similar frequency in both groups. It is worth to emphasize that the patients that responded to the therapies had a smaller incidence of second neoplasms and Richter's transformation. ${ }^{25}$ Another randomized study, realized by this same group in 2010 with 817 patients diagnosed with CLL, compared the FC and FCR therapies, and it was found a mortality rate, due to the second neoplasia, that was 2 times bigger in the FC arm (15\%), when compared to the FCR $\operatorname{arm}(8 \%){ }^{26}$

In a phase Ib (NCT01300247), it was evaluated the efficacy and the safety of obinutuzumab-bendamutine (G-B) versus obinutuzumab-fludarabine-ciclofosfamide, in patients with CLL that had not received treatment yet by the time of the study. In a two years follow-up, it was diagnosed only one secondary neoplasia (a squamous cell carcinoma, in the G-B group). [27] There are some studies in progress that may predict the carcinogenic potential of the new therapeutic agents for CLL patients, such as the CLL 14 (NCT02242942) that analyze the efficacy and safety of obinutuzumab and venetoclas versus obinutuzumab and chlorambucil and the NCT02264574 study, that evaluate the results of obinutuzumab and chlorambucil versus obnituzumab and ibrutinib. ${ }^{28,29,30}$
$\mathrm{CCL}$ and association with others tumors by the time of the diagnosis: the most frequent neoplasms. Falchi et al. ${ }^{12}$ identified that $28 \%$ of patients with CLL showed a neoplasia a priori, and $8 \%$ of them received the diagnosis of CLL while investigating or treating other neoplasms. In those findings, the most frequent types of cancer were skin, lung, prostate, breast and gastrointestinal tract. ${ }^{12}$

\section{Richter's Syndrome}

The Richter's Syndrome (RS) is the transformation of CLL in Diffuse Large B- cell Lymphoma. ${ }^{13,30}$ The RS occurs in 2 to $10 \%$ of the CLL carriers, and it presents a reserved prognosis (the overall survival varies, in the literature, from 2 to 8 months), and the time passed between the diagnosis of CLL and the diagnosis of RS tends to fluctuate between 23 to 48 months. ${ }^{13,17,30,31}$ A clinical trial showed that the Richter's Transformation represented nearly $50 \%$ of deaths in patients with CLL that carried a trisomy of the chromosome 12.4

Besides that, it is known that the patients treated with FCR regimen + alemtuzumab as first-line therapy presented a higher incidence of Richter's Transformation (30\%), when comparing those who were treated exclusively with the FCR scheme $(2,7 \%) .{ }^{17}$

Carriers of CLL have two to five times greater chances to develop other lymphoproliferative neoplasia, fact that may be an important cause of morbimortality. $22,33,34,35$ This development is most frequently observed in male sex (3,4\% in men, against $1 \%$ in women), and it was not seen any difference related to other characteristics (such as age, disease stage or lymphocyte absolute count). ${ }^{22}$

A retrospective analysis realized at The Mayo Clinic, with 962 carriers of CLL, identified a frequency of 2,7\% of Lymphoproliferative Disease (LPD), and, among them, the Diffuse Large B-cell Lymphoma was the most common. The average time between the beginning of the treatment to CLL and the developing of a second LPD varied from two to four years. Despite the fact that the association between alkylating agents and the risk of developing Myelodysplastic Syndrome and/or Acute Myeloid Leukemia is well known, these medications did not increase the risk of second LPD in the patients that were followed. These results confirm the importance of delaying the onset of therapy until the patients fit the criteria established for starting treating. The association of a second LPD with specifics types of therapy (those using purine analogs and anthracyclines) corroborate de thesis that the kind of medication that is used has greater relation with the development of LPD than the biologic characteristics of the disease. ${ }^{22}$

The CD4 count decreases rapidly after the treatment with purine analogs, and they may continue to fall one year after the end of therapy. This immunosuppression may allow the growth of new lymphoid clones, 
preventing the action of Natural Killers (NK) cells. In some cases, the decay of the absolute T-lymphocyte count can also allow the proliferation of clones infected by the Epstein-Barr Virus (EBV), fact that could foment the appearance of a second LPD. ${ }^{36,37}$
There are also others hematologic neoplasms described in CLL patients (in addition to those that have already been quoted in the text), such as hairy-cell leukemia, Hodgkin's Lymphoma, T-cell Lymphoma and Lymphoblastic Lymphoma.

\section{CONCLUSION}

It is clear that the carriers of Chronic Lymphocytic Leukemia tend to show a higher risk of developing other neoplasms, when compared to the general population. The discovery of this new neoplasia may be realized before, at the moment, or after the diagnosis of CLL.

Furthermore, it is known that the second tumors more prevalent in CLL patients are similar to those that are found in previously healthy patients, with a particular emphasis in skin, breast, prostate and lung cancers. This relation corroborates the hypothesis that the prolonged immunosuppression related to the leukemia, added to the carcinogenic potential of chemotherapeutic and radiotherapeutics drugs, may have an important role in the genesis of the second neoplasia, that can be solid or hematological.

The careful surveillance at the follow-up is extremely necessary. This monitoring needs to be even more cautious in the group of greater risk: men, elderly and thrombocytopenic. In this context, the clinical monitoring is one of the most essential features to perform an early diagnosis of the second neoplasms.

\section{METODOLOGY}

The scientific research was performed after reviewing the papers that were published in the literature between 1998 and 2017, using online databases.

\section{REFERENCES}

1. Rossi D, Gaidano G. The clinical implications of gene mutations in chronic lymphocytic leukaemia. Br J Cancer. 2016;114(8):849-54.

2. Robak T, Stilgenbauer S, Tedeschi A. Front-line treatment of CLL in the era of novel agents. Cancer Treat Rev. 2017;53:70-8.

3. Melton MF, Pearlman AN. Chronic lymphocytic leukemia of the oropharyngeal cavity and paranasal sinuses: a case series and literature review. Int Forum Allergy Rhinol. 2015;5(11):1055-8.

4. Visentin A, Imbergamo S, Gurrieri C, Frezzato F, Trimarco V, Martini V, et al. Major infections, secondary cancers and autoimmune diseases occur in different clinical subsets of chronic lymphocytic leukaemia patients. Eur J Cancer. 2017;72:103-11.

5. Tsimberidou AM, Wen S, McLaughlin P, O'Brien S, Wierda WG, Lerner $S$, et al. Other malignancies in chronic lymphocytic leukemia/ small lymphocytic lymphoma. J Clin Oncol. 2009;27(6):904-10.

6. Maurer $\mathrm{C}$, Langerbeins $\mathrm{P}$, Bahlo J, Cramer P, Fink AM, Pflug $N$, et al. Effect of first-line treatment on second primary malignancies and Richter's transformation in patients with CLL. Leukemia. 2016;30(10):2019-25.
7. Morton LM, Curtis RE, Linet MS, Bluhm EC, Tucker MA, Caporaso N, et al. Second malignancy risks after non-Hodgkin's Iymphoma and chronic lymphocytic leukemia: differences by lymphoma subtype. J Clin Oncol. 2010;28(33):4935-44.

8. Molica S. Second neoplasms in chronic Iymphocytic leukemia: incidence and pathogenesis with emphasis on the role of different therapies. Leuk Lymphoma. 2005;46(1):49-54.

9. Kyasa MJ, Hazlett L, Parrish RS, Schichman SA, Zent CS. Veterans with chronic lymphocytic leuke$\mathrm{mia} / \mathrm{small}$ lymphocytic lymphoma (CLL/SLL) have a marked ly increased rate of second malignancy, which is the most common cause of death. Leuk Lymphoma. 2004;45(3):507-13.

10. Cheson BD, Vena DA, Barrett J, Freidlin B. Second malignancies as a consequence of nucleoside analog therapy for chronic lymphoid leukemias. J Clin Oncol. 1999;17(8):2454-60.

11. Royle JA, Baade PD, Joske D, GirschikJ, Fritschi L. Second cancer incidence and cancer mortality among chronic lymphocytic leukaemia patients: a population-based study. Br J Cancer. 2011;105(7):1076-81.

12. Falchi L, Vitale C, Keating MJ, Lerner S, Wang $X$, Elhor Gbito KY, et al. Incidence and prognostic impact of other cancers in a population of longterm survivors of chronic lymphocytic leukemia. Ann Oncol. 2016:27(6):1100-6. 
13. Robak T. Second malignancies and Richter's syndrome in patients with chronic lymphocytic leukemia. Hematology. 2004;9(5-6):387-400.

14. Robak E, Robak T. Skin lesions in chronic lymphocytic leukemia. Leuk Lymphoma. 2007;48(5):855-65.

15. Solomon BM, Rabe KG, Slager SL, Brewer JD, Cerhan JR, Shanafelt TD. Overall and cancer-specific survival of patients with breast, colon, kidney, and lung cancers with and without chronic lymphocytic leukemia: a SEER population-based study. J Clin Oncol. 2013;31(7):930-7.

16. Hisada M, Biggar RJ, Greene MH, Fraumeni JF Jr, Travis LB. Solid tumors after chronic lymphocytic leukemia. Blood. 2001;98(6):1979-81.

17. Benjamini $O$, Jain $P$, Trinh L, Qiao W, Strom SS, Lerner $S$, et al. Second cancers in patients with chronic lymphocytic leukemia who received frontline fludarabine, cyclophosphamide and rituximab therapy: distribution and clinical outcomes. Leuk Lymphoma. 2015;56(6):1643-50.

18. Hisada M, Biggar RJ, Greene MH, Fraumeni JF Jr, Travis LB. Solid tumors after chronic lymphocytic leukemia. Blood. 2001;98(6):1979-81.

19. Tabuteau S, Garidi R, Fernandes J, Vaida I, Capiod JC, Legrand S, et al. Fludarabine (FAMP) and risk of occurrence of Richter's syndrome among B-CLL. Blood. 2000;96:295B.

20. Thornton PD, Bellas C, Santon A, Shah G, Pocock C, Wotherspoon AC, et al. Richter's transformation of chronic lymphocytic leukemia: The possible role of fludarabine and the Epstein-Barr virus in its pathogenesis. Leuk Res. 2005;29(4):389-95.

21. Mauro FR, Foa R, Giannarelli D, Cordone I, Crescenzi S, Pescarmona E, et al. Clinical characteristics and outcome of young chronic lymphocytic leukemia patients: a single institution study of 204 cases. Blood. 1999;94(2):448-54.

22. Maddocks-Christianson K, Slager SL, Zent CS, Reinalda M, Call TG, Habermann TM, et al. Risk factors for development of a second lymphoid malignancy in patients with chronic lymphocytic leukaemia. $\mathrm{Br} J$ Haematol. 2007;139(3):398-404.

23. Morrison VA, Rai KR, Peterson BL, Kolitz JE, Elias $\mathrm{L}$, Appelbaum FR, et al. Therapy-related myeloid leukemias are observed in patients with chronic lymphocytic leukemia after treatment with fludarabine and chlorambucil: results of an intergroup study, cancer and leukemia group B 9011. J Clin Oncol. 2002;20(18):3878-84.

24. Dighiero G, Maloum K, Desablens B, Cazin B, Navarro M, Leblay $R$, et al. Chlorambucil in indolent chronic lymphocytic leukemia. French Cooperative Group on Chronic Lymphocytic Leukemia. N Engl J Med. 1998;338(21):1506-14.
25. Fischer K, Bahlo J, Fink AM, Goede V, Herling CD, Cramer $\mathrm{P}$, et al. Long-term remissions after FCR chemoimmunotherapy in previously untreated patients with CLL: updated results of the CLL8 trial. Blood. 2016;127(2):208-15.

26. Hallek M, Fischer K, Fingerle-Rowson G, Fink AM, Busch R, Mayer J, et al.; International Group of Investigators; German Chronic Lymphocytic Leukaemia Study Group. Addition of rituximab to fludarabine and cyclophosphamide in patients with chronic lymphocytic leukaemia: a randomised, open-label, phase 3 trial. Lancet. 2010;376(9747):1164-74.

27. Brown J, O’Brien S, Kingsley CD, Eradat H, Pagel JM, Lymp J, et al. Obinutuzumab plus fludarabine/ cyclophosphamide or bendamustine in the initial therapy of CLL patients: the phase $1 \mathrm{~b}$ GALTON trial. Blood. 2015;125(18):2779-85.

28. Goede V, Fischer K, Busch R, Engelke A, Eichhorst $B$, Wendtner CM, et al. Obinutuzumab plus chlorambucil in patients with CLL and coexisting conditions. N Engl J Med. 2014;370(12):1101-10.

29. Al-Sawaf O, Fischer K, Engelke A, Pflug N, Hallek M, Goede V. Obinutuzumab in chronic lymphocytic leukemia: design, development and place in therapy. Drug Des Devel Ther. 2017; 11:295-304.

30. Tobinai K, Klein C, Oya N, Fingerle-Rowson G. A Review of Obinutuzumab (GA101), a Novel Type II Anti- CD20 Monoclonal Antibody, for the Treatment of Patients with B-Cell Malignancies. Adv Ther. 2017;34(2):324-56.

31. Jain $P$, O'Brien $S$. Richter's transformation in chronic lymphocytic leukemia. Oncology (Williston Park). 2012;26(12):1146-52.

32. Jamroziak K, Tadmor T, Robak T, Polliack A. Richter syndrome in chronic lymphocytic leukemia: updates on biology, clinical features and therapy. Leuk Lymphoma. 2015;56(7):1949-58.

33. Giles FJ, O’Brien SM, Keating MJ. Chronic lymphocytic leukemia in (Richter's) transformation. Semin Oncol. 1998;25(1):117-25.

34. Schöllkopf C, Rosendahl D, Rostgaard K, Pipper C, Hjalgrim $\mathrm{H}$, et al. Risk of second cancer after chronic lymphocytic leukemia. Int J Cancer. 2007;121(1):151-6.

35. Nakamura N, Abe M. Richter syndrome in B cell chronic lymphocytic leukemia. Pathol Int. 2003;53(4):195-203.

36. Lazzarino $M$, Orlandi $E$, Baldanti F, Furione $M$, Pagnucco G, Astori C, et al. The immunosuppression and potential for EBV reactivation of fludarabine combined with cyclophosphamide and dexamethasone in patients with lymphoproliferative disorders. Br J Haematol. 1999;107(4):877-82. 
37. Kanzler $H$, Küppers $R$, Helmes $S$, Wacker $H H$, Chott A, Hansmann ML, et al. Hodgkin and ReedSternberg-like cells in B-cell chronic lymphocytic leukemia represent the outgrowth of single germinal-center B-cell-derived clones: potential precursors of Hodgkin and Reed-Sternberg cells in Hodgkin's disease. Blood. 2000;95(3):1023-31.

38. Robak T, Blonski JZ, Gora-Tybor J, Kasznicki M, Konopka L, Ceglarek B, et al. Second malignancies and Richter's syndrome in patients with chronic lymphocytic leukaemia treated with cladribine. Eur J Cancer. 2004;40(3):383-9.

39. Ito S, Fujiwara SI, Mashima K, Umino K, Minakata $D$, Nakano $H$, et al. Development of acute myeloid leukemia in patients with untreated chronic lymphocytic leukemia. Ann Hematol. 2017;96(5):719-24. 